\title{
Control method of unfavorable speed interval for high-speed trains
}

\author{
Lindong WANG*, Qiang HUANG, Yuqing ZENG, Fengtao LIN \\ China Academy of Railway Sciences, Locomotive and Car Research Institute, Beijing 100081, China
}

\begin{abstract}
In tests on dynamic performance of high-speed trains, it is found that there is an unfavorable speed interval for some vehicles, which would be harmful to the daily operation of the vehicle. By analyzing the relationship of vibration frequencies of the vehicle and its running speed, this paper finds that the unfavorable speed interval is caused by the vibration superposition of the natural frequency of the vehicle system with the frequency of external excitation. Taking some electric multiple units (EMUs) as examples, we proposed an approach to obtaining the unfavorable speed interval of vehicles. By analyzing the relation between vibration frequencies and the running speed of the vehicle, the natural frequencies of the vehicle system and the external excitations are distinguished. In the end, we suggest some measures to minimize the negative influences of the unfavorable speed interval, such as shifting frequency, reducing or eliminating external excitation.
\end{abstract}

Key words: high-speed trains; unfavorable speed interval; dynamic performance

(C) 2012 JMT. All rights reserved.

\section{Introduction}

$\mathrm{I}$ $\mathrm{n}$ tests on dynamic performance of high-speed trains, the performance usually becomes worse with the increase of running speed [1-2]. Sometimes, the dynamic performance of trains decreases greatly in a certain interval of running speed and becomes better when beyond the interval [3-4]. The speed interval in which the dynamic performance of the vehicle becomes greatly worse is defined as the unfavorable speed interval [5]. Fig. 1 shows the variation of dynamic performance of a certain vehicle with respect to its running speed [5]. A peak response was observed at the speed of $V_{\mathrm{b}}$, and the response of the vehicle increased obviously around the speed of $V_{\mathrm{b}}$, which means that the performance significantly worsens around the speed of $V_{\mathrm{b}}$.

Fig. 2 shows the variation of the measured vertical ride comfort index $(\mathrm{RCI})$ with respect to speed of a $380 \mathrm{~km} / \mathrm{h}$ train in the Zaozhuang-Bengbu section of the Beijing-Shanghai high-speed railway. One can see that the range of $330-390 \mathrm{~km} / \mathrm{h}$ is the unfavorable speed interval, in which the values of the vertical RCI are much larger than those at other speeds.

Received Dec. 29, 2011; revision accepted Feb. 28, 2012

*Corresponding author. E-mail: 13521785825@139.com (L.D. WANG)

(C) 2012 JMT. All rights reserved doi: 10.3969/j.issn.2095-087X.2012.03.005
Fig. 3 shows the variation of lateral RCI with respect to speed of a $250 \mathrm{~km} / \mathrm{h}$ train running on the BeijingShanghai high-speed railway. One can see that the range

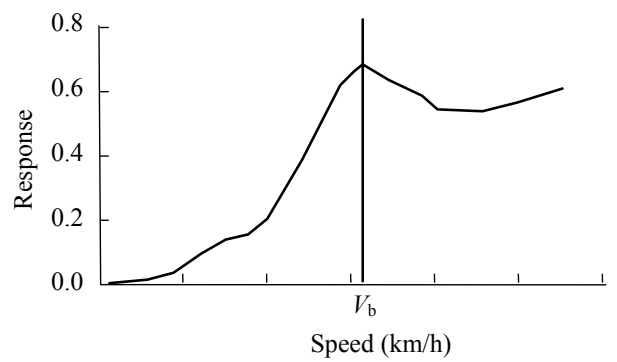

Fig. 1 Scheme of unfavorable speed interval [5]

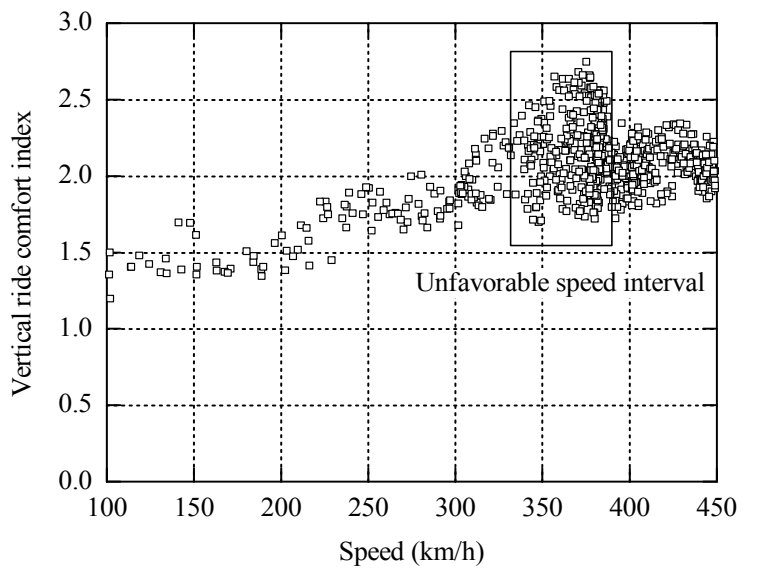

Fig. 2 Vertical RCI for a $380 \mathrm{~km} / \mathrm{h}$ train 


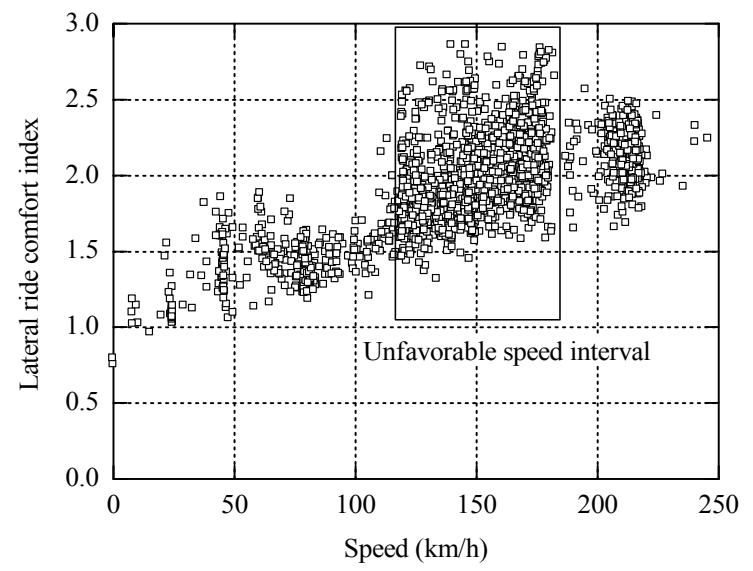

Fig. 3 Lateral RCI for a $250 \mathrm{~km} / \mathrm{h}$ train

of $120-180 \mathrm{~km} / \mathrm{h}$ is the unfavorable speed interval, in which the values of the lateral RCI are much larger than those at other speeds, too.

These two unfavorable speed intervals are wide and cover the key speed grades of trains, so it is necessary to solve the problem of unfavorable speed interval of vehicles.

Long-term practices have identified the problems of the unfavorable speed interval [6-7]. Refs. [8-9] studied the cause of unfavorable speed interval and concluded that it was closely related to the natural frequency of the vehicle or its components. Some measures to relieve the problem were found, such as amending damping coefficients and elasticity modulus [10-12]. However, most research aims at some specific components or adjusting the parameters of the vehicle, and these approaches are all based on the researchers' experience. To the best knowledge of the authors, there are still no effective methods to solve this problem.

In this paper, we first analyze the cause of unfavorable speed interval. Then by analyzing the relation between vibration frequencies and running speed of the vehicle, we distinguish the natural frequencies of the vehicle system, and find out the origin of external excitation. On this basis, we present an approach to solve the problem of unfavorable speed interval. Finally, we suggest some measures to minimize the negative influences of unfavorable speed interval.

\section{Cause of unfavorable speed interval}

Fig. 4 shows the frequency spectrums of a vehicle at different train speeds. There are two dominating frequencies: one is irrelevant to running speed, which may be one certain natural frequency of the vehicle; the other increases with speed, which may be caused by the characteristics of the vehicle or external excitation. The two frequencies intersect in the circle as shown in Fig. 4, where the dynamic performance becomes worse. The speeds that fall within the intersection are unfavorable.
Thus, unfavorable speed interval is caused by the vibration superposition of two frequencies in the vehicle system.

To avoid the unfavorable speed interval, the first-order vertical bending frequency, and the frequencies of all modes, even the natural frequencies of every component, should not intersect with the frequencies which increase with the running speed. This criterion is suitable for the analysis of high-order mode of trains and also for the structure mode and suspension mode of the components [13].

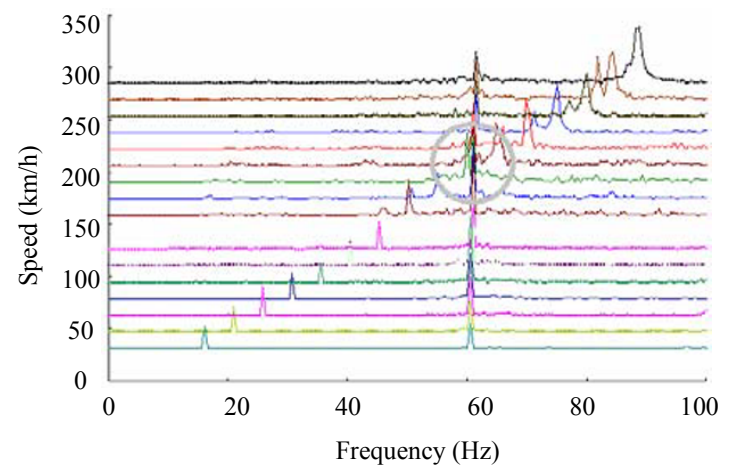

Fig. 4 Relation between frequency and running speed

\section{Distinguishing frequencies of vehicle sys- tem and external excitation}

Since the unfavorable speed interval is caused by the vibration superposition of two frequencies, the key is to distinguish the two vibration frequencies by analyzing vehicles' response data obtained through experimental or numerical simulation [14]. Inversion of the response curve using dynamics is a valid method.

\subsection{Analysis on vertical RCI in unfavorable speed interval}

The vertical acceleration of a $380 \mathrm{~km} / \mathrm{h}$ train in unfavorable speed interval is shown in Fig. 5. There is an apparent periodical vibration of acceleration.

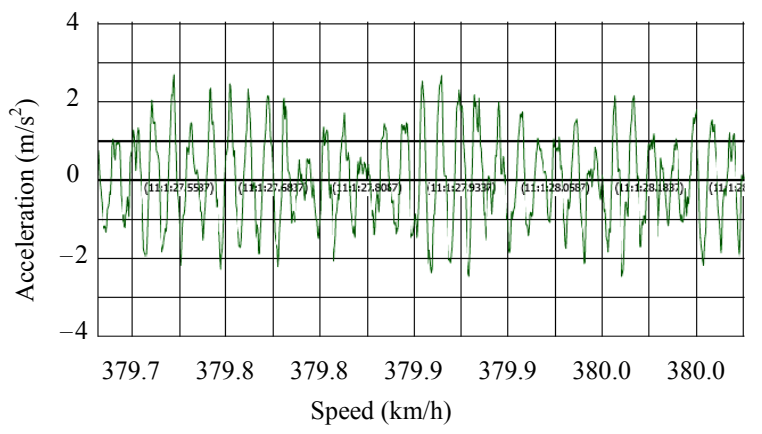

Fig. 5 Vertical acceleration of vehicle in unfavorable speed interval 
Fig. 6 shows the analysis diagram of the vertical vibration of the car body.

Firstly, the frequencies which are almost invariable with the running speed are distinguished from the measured data of vibration acceleration, as shown in Fig. 7. It is shown in the figure that several local peak values are not related to speed in the vertical vibration of the car body. Those peak values reflect the natural frequencies of the system, such as $0.977 \mathrm{~Hz}, 10.376 \mathrm{~Hz}, 20.386 \mathrm{~Hz}$, $32.471 \mathrm{~Hz}, 35.645 \mathrm{~Hz}$, and so on. The frequencies ranging from 32 to $40 \mathrm{~Hz}$ are the most dominant.

Secondly, the frequencies related to running speed are distinguished from the measured data of vibration acceleration, as shown in Fig. 8. Several local peak values varied with the running speed in the vertical vibration of the car body. Those peak values reflect the existence of external excitations. The identified external excitations are periodic excitations with the length of approximately $2.787 \mathrm{~m}, 6.494 \mathrm{~m}, 3.236 \mathrm{~m}$ and $2.688 \mathrm{~m}$ (here the frequency of excitation is represented by length, referring to the description of track irregularity). Among all the excitations, the periodic excitation with the length of approximately $2.688 \mathrm{~m}$ is the most obvious, and $3.236 \mathrm{~m}$ ranks the second.

After discriminating the natural frequencies of the vehicle and external excitation frequencies, one can analyze the relationship between the two frequencies. Fig. 9 shows the resonance points of the vertical vibration of the vehicle with external excitations. It is observed that there are several resonance points in the range from $300 \mathrm{~km} / \mathrm{h}$ to $380 \mathrm{~km} / \mathrm{h}$. The resonance points are as follows: (1) vertical vibration frequency of vehicle equals $32.471 \mathrm{~Hz}$ and external excitation has the length of $2.688 \mathrm{~m}$ when running speed is $314 \mathrm{~km} / \mathrm{h}$; (2) vertical vibration frequency of vehicle equals $32.471 \mathrm{~Hz}$ and external excitation has the length of $3.236 \mathrm{~m}$ when running speed is $378 \mathrm{~km} / \mathrm{h}$; (3) vertical vibration frequency of vehicle equals $32.471 \mathrm{~Hz}$ and external excitation has the length of $2.688 \mathrm{~m}$ when running speed is $345 \mathrm{~km} / \mathrm{h}$.

As the system frequencies in the range from $32 \mathrm{~Hz}$ to $40 \mathrm{~Hz}$ shown in Fig. 7 are relatively obvious, the running speed interval, in which the resonance between system and excitation occur, would be more wide and mainly in the range of $310-390 \mathrm{~km} / \mathrm{h}$. The result is almost consistent with the measured unfavorable speed interval of vertical RCI in Fig. 2. Besides, the resonance of lower frequencies becomes not obvious as running speed decreases.

According to the wavelength and frequency characteristics of external excitation, the excitation source can

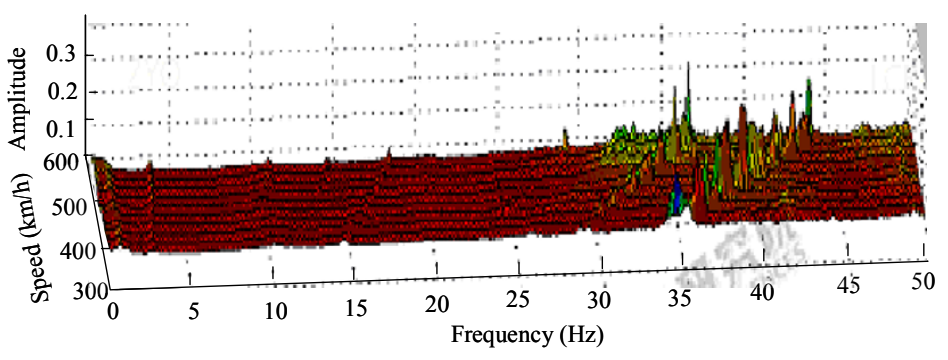

Fig. 6 Analysis diagram of vertical vibration of car body

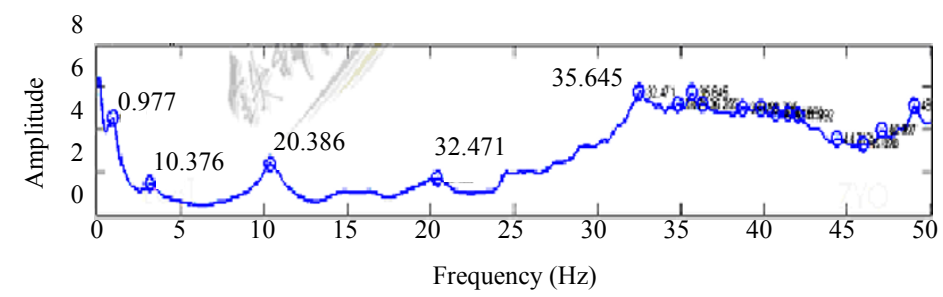

Fig. 7 Frequencies not related to running speed

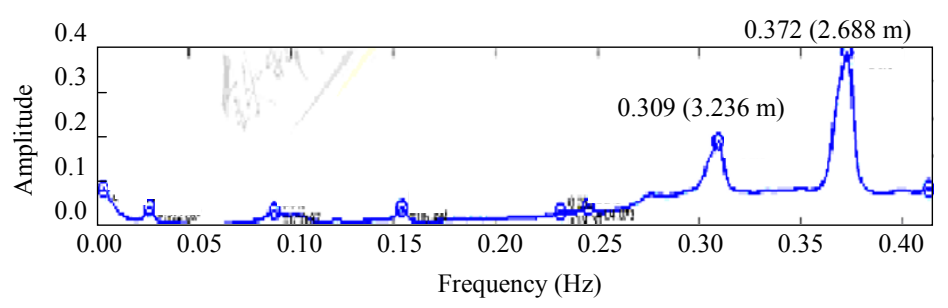

Fig. 8 Frequencies related to running speed 


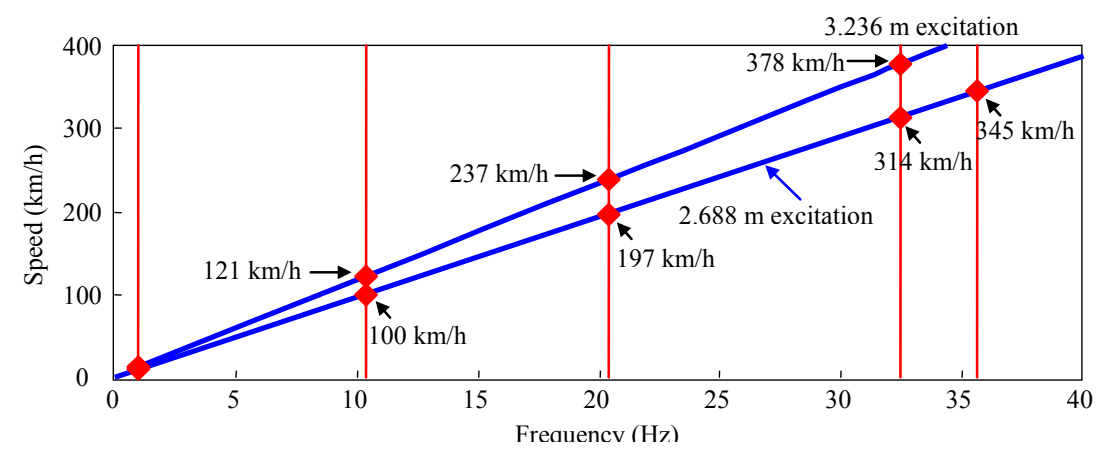

Fig. 9 Resonance points of vertical vibration of vehicle with external excitations

be distinguished. The excitation sources mainly include two aspects: one are the factors not related to the vehicle, such as track structure, road bed, wind load, etc; the other source are related to the structures of the vehicle, such as wheel profile and wheel dynamic unbalance, etc. Next the causes of excitations with the length of $2.688 \mathrm{~m}$ and $3.236 \mathrm{~m}$ are discussed. The perimeter of the wheel is approximately $2.7 \mathrm{~m}$, which is close to the excitation of length $2.688 \mathrm{~m}$. The railway in the experiment is high-speed unballasted track and rail plate of CRTSII type. The length of the rail plate is $6.45 \mathrm{~m}$, nearly the double of the excitation length $3.236 \mathrm{~m}$. Considering the wheelset wear, gap between rail plates and measurement errors, the wavelengths of $2.688 \mathrm{~m}$ and $3.236 \mathrm{~m}$ are derived from the excitation of wheel dynamic unbalance and rail plate, respectively.

\subsection{Analysis on lateral RCI in unfavorable speed interval}

The typical lateral acceleration of the vehicle of a
$250 \mathrm{~km} / \mathrm{h}$ train in unfavorable speed interval is shown in Fig. 10. There is an apparent periodical vibration of acceleration. Fig. 11 shows the analysis diagram of the lateral vibration of the car body. The frequencies are distinguished in Figs. 12 and 13 for frequency not related and related to speed, respectively.

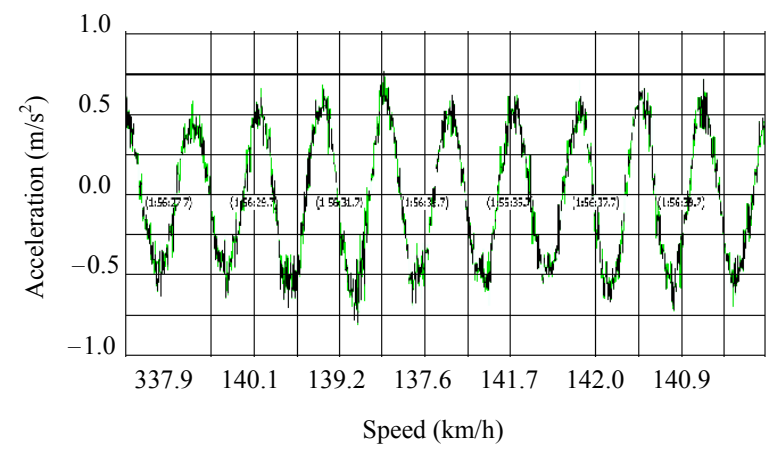

Fig. 10 Lateral acceleration of vehicle in unfavorable speed interval

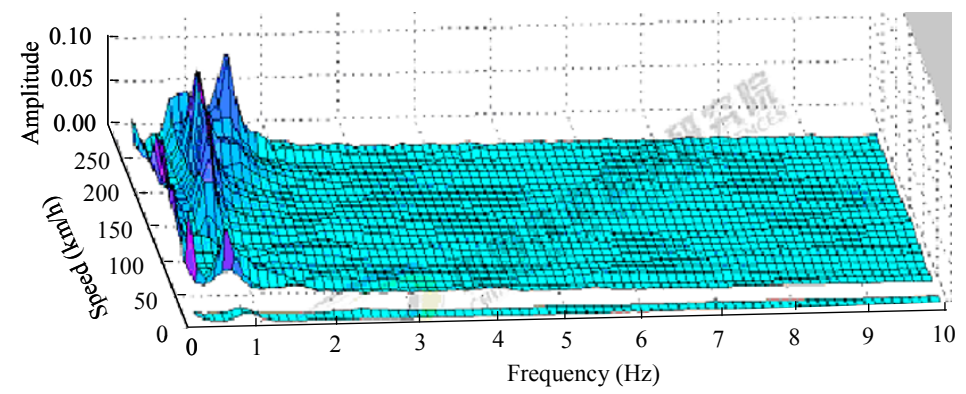

Fig. 11 Analysis diagram of lateral vibration of the car body

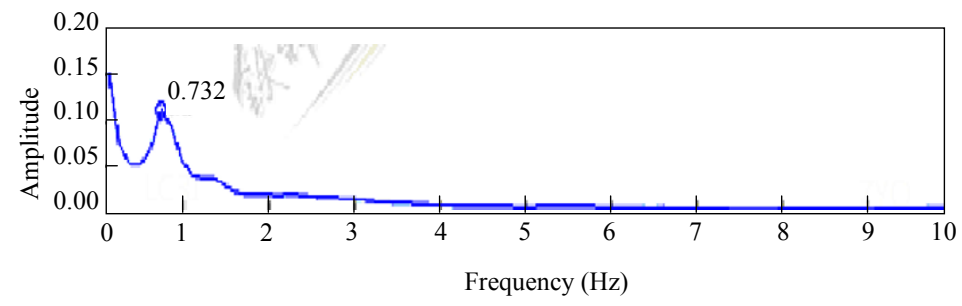

Fig. 12 Frequencies not related to speed 


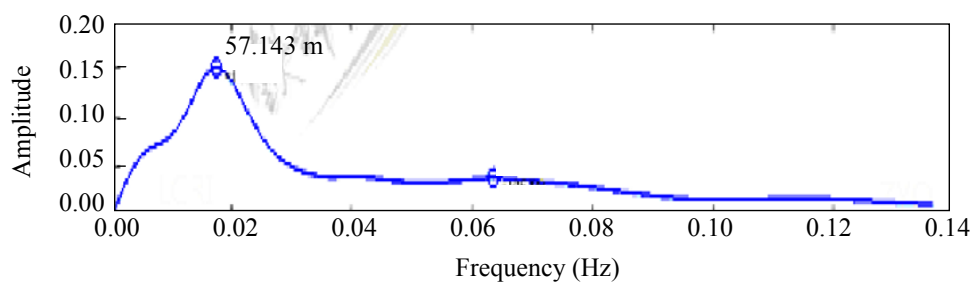

Fig. 13 Frequencies related to speed

In Fig. 12, one can see that there is a local peak value not varying with running speed in the lateral vibration of the car body, at $0.732 \mathrm{~Hz}$.

In Fig. 13, one can see that a local peak value varies with running speed in the lateral vibration of the car body and the wavelength is about $57.143 \mathrm{~m}$. That means there is a periodic external excitation of wavelength of approximately $57.143 \mathrm{~m}$.

Similarly, Fig. 14 shows the resonance point of the lateral vibration of the vehicle with external excitations. One can see that the resonance occurred at the speed of $151 \mathrm{~km} / \mathrm{h}$. At this speed, the lateral vibration of the vehicle increases, and the lateral RCI worsens. This may be the reason that the measured unfavorable speed interval in Fig. 3 is in the range of $120-180 \mathrm{~km} / \mathrm{h}$. This interval is so wide that it is not reasonable to consider the resonance point only in vehicle design.

After the analysis of lateral acceleration of bogie and axle-box, we find a periodic excitation with wavelength of approximately $57 \mathrm{~m}$. That means that the excitation source may be the snaking motion with a low frequency of wheel-rail.

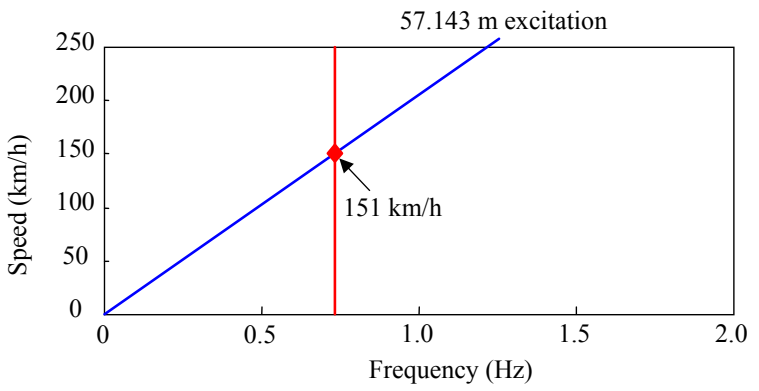

Fig. 14 Resonance point of lateral vibration of vehicle with external excitations

\section{Control method}

When the dynamic performance drops greatly in some intervals of speed, adjusting damping coefficient [15] is often used to improve the dynamic performances. This method can take effects to some extent, but the fact that the dynamic performances still varying with running speed is not changed.
The car body vibration in the unfavorable speed interval is mainly induced by the superposition of excitation frequency and system natural frequency. The vibration equation for the vehicle can be simplified as a onedegree-of-freedom forced vibration by the action of periodic force $F$ :

$$
\ddot{x}(t)+2 \delta \dot{x}(t)+\omega_{0}^{2} x(t)=\frac{F}{m} \cos \omega_{p} t,
$$

where the damping coefficient $\delta=C /(2 m)$, the natural angle frequency of the system

$$
\omega_{0}=\sqrt{\frac{k}{m}},
$$

and $\omega_{p}$ is the frequency of the excitation force. Symbols $m, C$ and $k$ represent the mass of body, drag coefficient, and stiffness coefficient, respectively. The solution of Eq. (1) consists of the transient solution and stationary solution, corresponding to the damped vibration and simple harmonic vibration, respectively.

After long-term vibration attenuation, the forced vibration could be simplified to be a simple harmonic vibration:

$$
x(t)=A \cos \left(\omega_{p} t+\phi\right),
$$

where

$$
\begin{aligned}
& A=\frac{F}{m \sqrt{\left(\omega_{0}^{2}-\omega_{p}^{2}\right)^{2}+4 \delta^{2} \omega_{p}^{2}}}, \\
& \phi=\operatorname{arctg} \frac{-2 \delta \omega_{p}}{\omega_{0}^{2}-\omega_{p}^{2}} .
\end{aligned}
$$

From Eqs. (3) and (4), we can see that the amplitude $A$ and phase angle $\phi$ are both related to the damping coefficient $\delta$, and that the external excitation frequency $\omega_{p}$ is not related to damping coefficient. The amplitude of vibration can be decreased to some extent by adjusting damping coefficient, but it is impossible to change the vibration frequency; in other words, it is difficult to eliminate the unfavorable speed interval. Fig. 15 [5] shows the effect of adjusting the damping coefficient. The curves of response 1 and response 2 represent the 


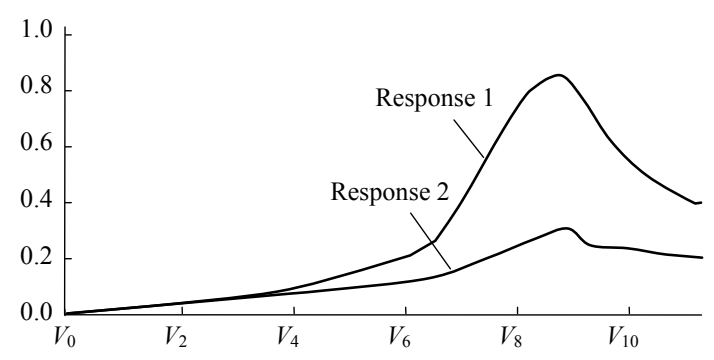

Fig. 15 Dynamic performance response of vehicle adjusted damping coefficient [5]

response of the vehicle before and after adjusting the damping coefficient, respectively. One can see that the amplitude of response 2 is lower than that of response 1 . However, the amplitude of response is still large when the train speed equals $V_{8}$. In this condition, the damping coefficient will soon become larger and the dynamic performance will become worse.

To solve the problem of unfavorable speed interval, the valid method is to make the natural frequency not intersect with the variation frequencies; that is, shift any two frequencies $\omega_{0}$ and $\omega_{p}$ to the domain where the two frequencies cannot intersect with each other. Fig. 16 shows that the resonance points are moved out beyond the operating interval of running speed. To shift frequency $\omega_{0}$, it must adjust mass $m$ or stiffness $k$. It is convenient to adjust stiffness for the suspension system, and the mass or redistribute mass for the structure of the vehicle. However, when there are several natural frequencies of the vehicle, it is very difficult to shift frequency $\omega_{0}$. In this case, shifting frequency $\omega_{p}$ is considered.

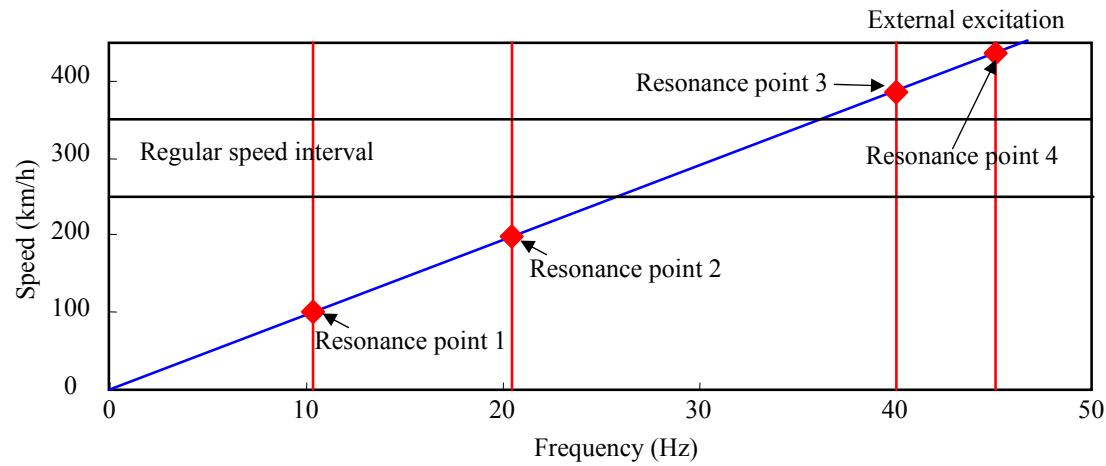

Fig. 16 The effect of shifting frequency method

When shifting frequency is difficult, distinguishing and effectively controlling the external excitation can improve the dynamic performance. For example, in the analysis of unfavorable speed interval in Fig. 2, we identified the external excitation of length $2.688 \mathrm{~m}$ caused by wheel dynamic unbalance. As the key speed grade of the train is in the range of $330-350 \mathrm{~km} / \mathrm{h}$, the excitation frequency of the wheelset is in the range of $34-36 \mathrm{~Hz}$, which is in the range of the sensitive frequency of the vehicle $(32-40 \mathrm{~Hz})$. The range of sensitive frequency is so wide that it is very difficult to change the wheelset excitation frequency. Thus, it is very difficult to solve the problem of unfavorable speed interval by shifting frequency (such as changing wheel diameter).

In engineering, an approach of weakening excitation is adopted to improve dynamic performances, namely, decrease the dynamic unbalance of the wheelset, which means decreasing the excitation force $F$ in Eq. (3).

Fig. 17 shows the car body vibration before and after decreasing external excitation. We can see that the car body vibration has been improved after decreasing external excitation.
Fig. 18 shows the vertical RCI of the vehicle after decreasing external excitation.

We can see that the unfavorable speed interval has been improved.
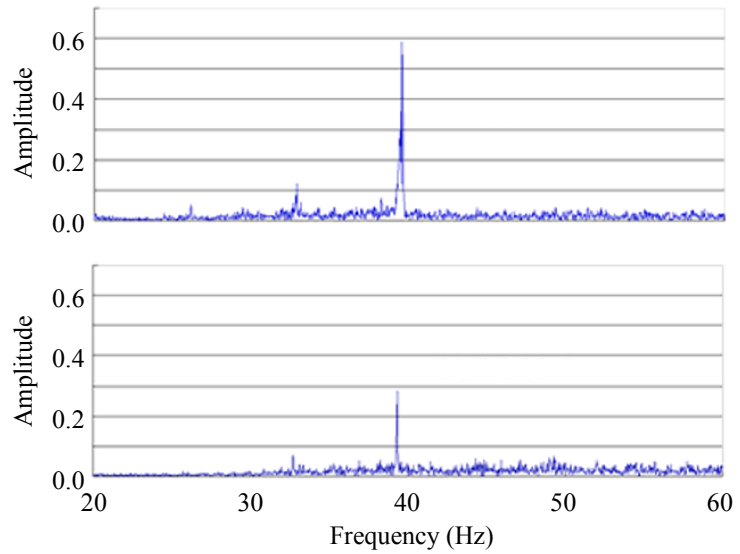

Fig. 17 Carbody vibration before and after decreasing external excitation 


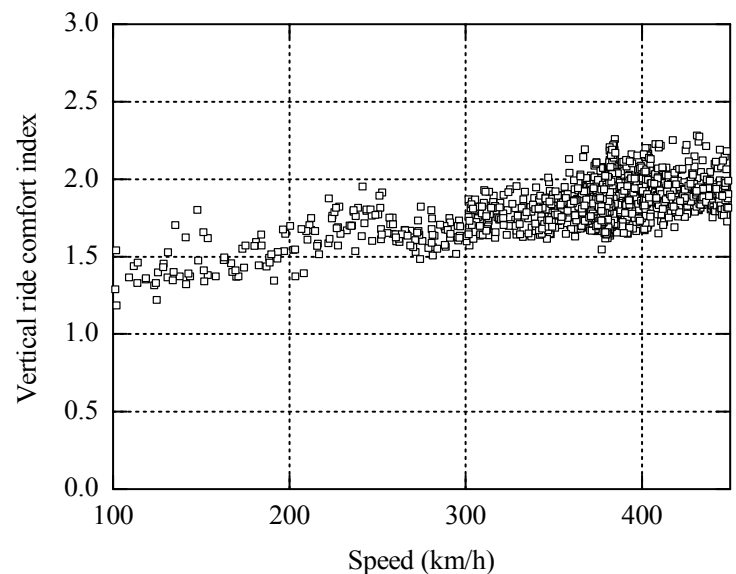

Fig. 18 The vertical RCI after decreasing external excitation

\section{Conclusions}

By decomposing the vibration frequencies of vehicle related to and not related to running speed, we distinguish the natural frequencies of system and frequencies of external excitation, and find that the unfavorable speed interval is caused by the vibration superposition of two frequencies.

Adjusting damping coefficient can improve the dynamic performance to some extent, but it cannot solve the problem of unfavorable speed interval thoroughly. Shifting frequency is the most valid approach to address the problem. When shifting frequency is difficult in practice, reducing or eliminating external excitation is also a valid way to minimize the negative influences of unfavorable speed interval.

\section{References}

[1] X. Kang, Y.M. Wang. L.D. Wang, et al., Research report on experiment of Beijing-Shanghai high-speed railway: experiment research of new type of high-speed EMU, Beijing: China Academy of Railway Sciences, 2011 (in Chinese).

[2] J.S. Zhou, L.H. Ren, G. Shen, Research on Ride Quality of High-speed Train, Mechanical Science and Technology, 2003, 22(6): 900-903 (in Chinese).
[3] Q. Huang, J. Liu, W.D. Wang, Analysis and evaluation on running safety of Speed Increased Freight Car, Railway Locomotive. 1997, 17(2): 7-11 (in Chinese).

[4] D. Chen, H.T. Chen, Dynamics analysis for CRH2 EMUs, Electric Drive for Locomotives, 2010(3): 13-16 (in Chinese).

[5] Q. Huang, Research on line experiment technology of high-speed train, In: 12th Annual Meeting of China Association for Science and Technology: Innovation and Development of High-Speed Train, Beijing, 2010: 27-31 (in Chinese).

[6] R.F. Yang, L.D. Wang, L. Zhang, EMU dynamic performance test and research on railway line, Railway Locomotive and Car, 2010, 30(1): 1-2 (in Chinese).

[7] Y. Yao, H.J. Zhang, Y. Luo, et al., Analysis on the torsional vibration of cardan shaft on CRH5 motor car, China Railway Science, 2009, 30(2): 82-85 (in Chinese).

[8] L.D. Wang, L. Zhang, Y.M. Wang, et al., Research on vertical vibration of car body when high-speed train passes the line with variable slope, In: Academic collections of 60th anniversary of China Academy of Railway Sciences, Beijing, Mar. 2, 2010, Beijing: China Railway Press (in Chinese).

[9] M.R. Chi, W.H. Zhang, J. Zeng, Vibration response characteristic of railway vehicle, Journal of Traffic and Transportation Engineering, 2007, 7(5): 6-11 (in Chinese).

[10] Q. Huang, D. Wu, Research on Improved Speed Scheme for Z8A bogie, China Railway Science, 1999, 21(3): 110 (in Chinese).

[11] K. Sasaki, The improvement of bogie support bearings based on vertical vibration of railway vehicle, JSME International Journal, Series C, 2008, 51: 137-147.

[12] L. Zhang, L.D. Wang, X. Huang, et al., Importance of EMU dynamic response test in systems integration test, Railway Locomotive and Car, 2011, 31(1): 41-44 (in Chinese).

[13] Q. Huang. Research on analysis equations of high-speed EMU system, In: Academic collections of 60th anniversary of China Academy of Railway Sciences, Beijing, Mar. 2, 2010, Beijing: China Railway Press (in Chinese).

[14] W.M. Zhai, Vehicle-track Coupling Dynamics, 2nd edition, Beijing: China Railway Press, 2002 (in Chinese).

[15] W.W. Ma, X.S. Xie, S.M. Tan, et al., Physics, 15th edition, Beijing: Higher Education Press, 2000 (in Chinese).

(Editor: Dongju CHEN) 